\title{
Back pain following epidural anaesthesia in labour
}

Ron Butler MD FRCPC, * John Fuller MD FRCPC $\dagger$

Purpose: To determine the factors associated with the development of post-partum back pain following epidural anaesthesia for labour and delivery and its incidence.

Methods: A prospective observational cohort study was conducted in a University affiliated tertiary care hospital. Women presenting for labour and delivery who were planning to have epidural anaesthesia were eligible for study. Baseline data were obtained from the women and obstetrical and anaesthetic data from the hospital chart. Women were contacted by phone at four to six weeks post-partum and questioned regarding the presence of any back pain and pain lasting longer than 14 days.

Results: Three hundred women entered the study and follow-up was obtained in $270(90 \%)$. The incidence of back pain was $30.7 \%$ and back pain lasting longer than 14 days was $8.5 \%$. Nulliparity was associated with a decreased risk of developing back pain post-partum but this decrease was only associated with pain lasting more than 14 days: Odds Ratio (OR) [95\% confidence interval] 0.32 [0.11-0.94]. A previous history of back pain was strongly associated with the development of any back pain (OR 43.85 [9.97- 192.9] but not with pain lasting longer than I4 days (OR 2.16 [0.71-6.58]). Age, weight and the duration of the second stage of labour were not associated with the development of back pain.

Conclusions: Back pain following epidural anaesthesia is common but persistent back pain is much less common. A previous history of back pain increases the likelihood of post-partum back pain following epidural anaesthesia. Nulliparity is associated with a decreased risk.

Objectif : Déterminer l'incidence du développement de lombalgie postpartum et les facteurs qui y sont associés, à la suite d'une anesthésie péridurale pendant le travail et l'accouchement.

Méthode : Une étude basée sur l'observation d'une cohorte a été menée dans un hôpital universitaire de soins tertiaires. Les femmes qui se sont présentées et qui avaient prévu une anesthésie péridurale pour le travail et l'accouchement étaient admissibles à cette étude. Les données de base ont été obtenues auprès des mères et les données obstétricales et anesthésiques provenaient du dossier hospitalier. Jointes par téléphone quatre à six semaines après l'accouchement, les femmes ont été interrogées sur la présence de lombalgie, et de douleur persistant plus de 14 jours.

Résultats : Trois cents femmes se sont inscrites à l'étude et une relance a été faite auprès de 270 d'entre elles (90\%). Lincidence de lombalgie était de $30,7 \%$, et de douleur au delà de 14 jours, de $8,5 \%$. La nulliparité a été associée à un risque plus faible de développer une lombalgie postpartum mais cette diminution concernait seulement la douleur persistant plus de 14 jours : coefficient de risque (CR) [intervalle de confiance de $95 \%$ ] de $0,32[0,11-0,94]$. Une histoire antérieure de lombalgie était fortement associée au développement de toute douleur au dos (CR de 43,85 [9,97-192,9] mais non d'une douleur de plus de I 4 jours (CR de 2, $16[0,71-6,58]$ ). Lâage, le poids et la durée de la deuxième phase du travail n'ont pas été reliés au développement de lombalgie.

Conclusion : La lombalgie qui suit une anesthésie péridurale est fréquente mais la douleur persistante l'est beaucoup moins. Une histoire antérieure de lombalgie accrôt la probabilité de lombalgie postpartum, à la suite d'anesthésie péridurale. II y a un risque plus faible chez les femmes nullipares. 
$\mathrm{E}$ PIDURAL anaesthesia has been widely used for pain relief during labour. In recent years, several studies have found an association between epidural anaesthesia and post-partum back pain. ${ }^{1,2}$ These studies, conducted in the UK, were retrospective surveys and have been criticized for their low response rates. More recently, several prospective studies have failed to find an association between post-partum back pain and epidural anaesthesia. ${ }^{3-6}$ The reported prevalence of back pain varied from study to study but was much higher in the prospective studies in the $\mathrm{US}^{3}$ and the $\mathrm{UK}^{6}$ than in the single study from Canada, ${ }^{4}$ raising the possibility of regional differences. All of these studies compared the incidence of post-partum back pain in epidural and non-epidural groups. They also identified other factors associated with the development of post-partum back pain including maternal age, maternal weight, nulliparity, a prolonged second stage of labour and a previous history of back pain. The specific factors that were associated with the development of post-partum back pain varied from study to study.

Identifying factors that increase the risk of post-partum back pain is important to help elucidate the mechanisms involved and also to inform patients appropriately of the risk of developing post-partum back pain.

The purpose of this study was to determine the factors associated with the development of post-partum back pain in women who received epidural anaesthesia for labour and delivery in a Canadian teaching hospital and to determine its incidence, using a prospective observational cohort design.

\section{Methods}

The study was approved by the ethics committee of The University of Western Ontario. Women presenting to St. Joseph's Health Centre, London, Ontario, for labour and delivery (spontaneous or induced) and who were planning to have epidural anaesthesia were eligible for this study. St. Joseph's Health Centre is a tertiary care obstetrical centre with a $24 \mathrm{hr}$ in-house epidural service provided by both anaesthesia residents and consultants. Potential subjects were asked if they would be willing to participate in a study of postpartum complications. The nursing personnel who recruited the patients and gathered the demographic data were unaware that the study was specifically about the occurrence of back pain. Following consent, demographic data and some baseline medical history questions were obtained from each study participant as well as a telephone number at which they could be reached in four to six weeks. Further information regarding their epidural anaesthesia and delivery was obtained from the hospital chart. Information from the chart regarding the epidural included: the time of insertion, position of the patient, whether the anaesthetist rated the procedure as easy or difficult, the number of attempts in placing the epidural catheter, and the presence or absence of paraesthesiae, venous cannulation and dural puncture. Obstetrical information obtained, included: duration of the second stage of labour, length of labour and whether forceps were used for rotation or delivery. Women who did not receive epidural anaesthesia or who underwent Caesarean section were excluded from further follow-up.

The epidural catheters were placed by resident and consultant staff. The epidural technique was not standardized, but the epidurals were started using \#17 Tuohy needles and most commonly the initial local anaesthetic was carbonated lidocaine. Epidural anaesthesia was maintained with intermittent boluses of bupivacaine $0.25 \%$. Supplemental epidural boluses of fentanyl were also employed. The use of infusions was not routine at this institution at the time these data were collected. The use of chloroprocaine was uncommon at this institution.

During the four to six week post-partum time interval the study participants were contacted by telephone and interviewed regarding the occurrence of back pain, its duration and the perception of how well their epidural worked and whether it was painful during its insertion. Other symptoms sought included: headache, numbness and weakness.

The results were analysed as the rate of occurrence of any back pain and pain lasting longer than two weeks. Pain lasting longer than two weeks was chosen because it is indicative of persistent and possibly disabling pain. These rates are presented with their $95 \%$ confidence interval for the entire cohort as well as the subset of patients with no previous history of back pain. Baseline characteristics of responders and non-responders were compared using a two sample $t$ test for continuous variables and Fisher's Exact Test for dichotomous variables. To investigate predictors of post-partum back pain, univariate analysis was carried out using Pearson's Chi-square test or Fisher's Exact test for each of the categorical variables. The continuous variables were assessed using univariate logistic regression. Factors associated with the outcome having a $P<0.25$ were then modelled using forward stepwise multiple logistic regression. ${ }^{7}$ Known important predictors from the literature were forced into the model (age, weight, duration of second stage, nulliparity and previous history of back pain). The presence of any pain and pain lasting for more than two weeks was both modelled for the entire cohort as well as for the subset with no previous history of back pain. The results are shown as the predicted odds ratio and their $95 \%$ confidence intervals. All analyses were performed with SAS $\otimes^{6} 6.09$, Cary NC. 
TABLE I Baseline Data

\begin{tabular}{|c|c|c|c|c|}
\hline \multicolumn{2}{|c|}{ Variable } & $\begin{array}{l}\text { Responders }(\mathrm{n}=270) \\
\text { Mean } \pm S D(\text { Range })\end{array}$ & $\begin{array}{l}\text { Non-responders }(\mathrm{n}=30) \\
M e a n \pm S D(\text { Range })\end{array}$ & $P$ \\
\hline \multicolumn{2}{|c|}{ Age (yr) } & $28.8 \pm 5.2$ & $26.2 \pm 4.3$ & 0.009 \\
\hline \multicolumn{2}{|c|}{ Weight $(\mathrm{kg})$} & $76.3 \pm 11.9(54-137)$ & $78.9 \pm 13.5(60-113)^{\star}$ & 0.323 \\
\hline \multicolumn{2}{|c|}{ Height $(\mathrm{cm})$} & $162.1 \pm 6.5(148-180)$ & $164.5 \pm 4.7(155-172)^{*}$ & 0.097 \\
\hline \multirow{2}{*}{\multicolumn{2}{|c|}{ Smokers }} & Frequency (\%) & Frequency (\%) & P \\
\hline & & $60(22.2)$ & $11(36.7)$ & 0.11 \\
\hline \multicolumn{2}{|c|}{ Previous history of back pain } & $29(10.7)$ & $0(0)$ & 0.094 \\
\hline \multicolumn{2}{|c|}{ Nulliparous } & $130(48.2)$ & $20(66.7)$ & 0.082 \\
\hline \multirow[t]{5}{*}{ Parity } & 0 & $130(48.1)$ & & \\
\hline & 1 & $97(35.9)$ & & \\
\hline & 2 & $33(12.2)$ & & \\
\hline & 3 & $9(3.3)$ & & \\
\hline & 4 & $1(0.4)$ & & \\
\hline
\end{tabular}

* missing values, $\mathrm{n}<30$

TABLE II $(\mathbf{n}=270)$ Epidural and Obstetric Data

\begin{tabular}{|c|c|c|c|}
\hline Variable & Mean & S.D. & Range \\
\hline $\begin{array}{l}\text { Duration of epidural } \\
\text { Duration } \\
\text { of second stage of labour }\end{array}$ & $\begin{array}{l}5.4 \mathrm{hr} \\
100.9 \mathrm{~min}\end{array}$ & $\begin{array}{l}3.7 \mathrm{hr} \\
76.0 \mathrm{~min}\end{array}$ & $\begin{array}{l}0.16-23.8 \mathrm{hr} \\
5-405 \mathrm{~min}\end{array}$ \\
\hline & & Frequency & Percent \\
\hline $\begin{array}{l}\text { casy placement of } \\
\text { epidural }\end{array}$ & & 251 & $93 \%$ \\
\hline venous cannulation & & 22 & $8.1 \%$ \\
\hline $\begin{array}{l}\text { required more than } \\
\text { onc attempt at placement }\end{array}$ & & 46 & $17 \%$ \\
\hline dural puncture & & 3 & $1.1 \%$ \\
\hline $\begin{array}{l}\text { paraesthesia at time } \\
\text { of epidural insertion }\end{array}$ & & 40 & $14.8 \%$ \\
\hline $\begin{array}{l}\text { patients assessment } \\
\text { that epidural insertion } \\
\text { painful }\end{array}$ & & 36 & $13.3 \%$ \\
\hline $\begin{array}{l}\text { patients assessment } \\
\text { that epidural worked }\end{array}$ & & 246 & $91.1 \%$ \\
\hline $\begin{array}{l}\text { use of forceps during } \\
\text { delivery }\end{array}$ & & 63 & $23.3 \%$ \\
\hline
\end{tabular}

\section{Results}

Women were recruited between June and October 1991. There were 300 women who met inclusion criteria and consented to be in the study. Follow-up was obtained on 270 women, for a response rate of $90 \%$. Those lost to follow up either moved, without leaving a forwarding address, or their telephone had been disconnected. The baseline data for the women are shown in Table I. The mean age was $28.8 \pm 5.2$ (SD) [17 -
43] range, yr. Forty-eight percent of the women were nulliparous and the majority of the other women had had only one previous baby. The range in parity was from 0 to 4 . The frequency of a previous history of back pain was $10.7 \%$. Non-responders were younger $(26.2 \pm 4.3$ yr $P=0.009)$ than responders. The nonresponders also tended to be taller, more likely to smoke, more likely to be nulliparous and less likely to have a previous history of back pain, although none of these characteristics reached statistical significance.

The data regarding the epidural and labour are presented in Table II. The mean duration of epidural use was $5.4 \pm 3.7[0.2-23.8] \mathrm{hr}$. The mean duration of the second stage of labour was $100.9 \pm 76.0$ [5-405] $\mathrm{min}$. Forceps were used in $23.3 \%$ of the deliveries.

Epidural placement was deemed easy by the anaesthetist $93 \%$ of the time, although there were 46 epidurals (17\%) that required more than one attempt at placement. The occurrence of complications associated with the insertion of the epidural were: dural puncture 3 (1.1\%), paraesthaesia on insertion 40 (14.8\%), and epidural vein cannulation $22(8.1 \%)$. At four to six weeks post-partum, $36(13.3 \%)$ of the women reported that the epidural insertion was painful and a total of $246(91.1 \%)$ reported that the epidural worked well for analgesia during labour.

The occurrence of any post-partum back pain and back pain lasting for longer than 14 days are shown in Table III. The presence of any post-partum back pain was reported by 83 (30.7\%) of the women (95\% CI 25.2 $-36.2 \%$ ). Excluding the women with a previous history of back pain, the incidence of any back pain was $23.2 \%$ (56/241) (17.7 -28.5\%). The number of women reporting pain lasting for longer than 14 days was substantially less $23 / 270(8.5 \%)(5.2-11.8 \%)$. When women with a previous history of back pain were exclud- 
TABLE III Occurrence of Back Pain

\begin{tabular}{llll}
\hline Variable & Frequency & Percent & $\begin{array}{c}\text { 95\% } \\
\text { Interval }\end{array}$ \\
\hline $\begin{array}{l}\text { entire cohort }(n=270) \\
\text { presence of any } \\
\text { back pain } \\
\text { pain lasting more } \\
\text { than } 14 \text { days }\end{array}$ & 83 & $30.7 \%$ & {$[25.2-36.2 \%]$} \\
$\quad 23$ & $8.5 \%$ & {$[5.2-11.8 \%]$} \\
$\quad \begin{array}{l}\text { excluding those with previous history of back pain }(n=241) \\
\text { presence of any } \\
\text { back pain }\end{array}$ & 56 & $23.2 \%$ & {$[17.7-28.5 \%]$} \\
$\begin{array}{l}\text { pain lasting for more } \\
\text { than } 14 \text { days }\end{array}$ & 18 & $7.5 \%$ & {$[4.2-10.8 \%]$} \\
\hline
\end{tabular}

TABLE IV ( $n=270)$ Logistic Regression Output: Entire Cohort

\begin{tabular}{lllll}
\hline & \multicolumn{2}{l}{$\begin{array}{c}\text { Any Back Pain } \\
\text { Days }\end{array}$} & \multicolumn{2}{l}{ Pain Longer than 14 } \\
& & & & \\
\hline Variable & OR & $95 \%$ CI & OR & $95 \%$ C.. \\
Age $/ \mathrm{yr}$ & 0.96 & {$[0.90-1.02]$} & 0.99 & {$[0.95-1.03]$} \\
Weight $/ \mathrm{kg}$ & 1.02 & {$[0.99-1.04]$} & 1.01 & {$[0.97-1.04]$} \\
Second Stage $/ \mathrm{hr}$ & 1.07 & {$[0.85-1.37]$} & 1.13 & {$[0.80-1.63]$} \\
nulliparity & 0.68 & {$[0.35-1.33]$} & $0.32^{*}$ & {$[0.11-0.94]$} \\
history of back pain & $43.85 *$ & {$[9.97-192.9]$} & 2.16 & {$[0.71-6.58]$} \\
\hline
\end{tabular}

* 95 \% C. I. excludes null value.

TABLE V ( $n=241$ ) Logistic Regression Output: Excluding women with a history of back pain

\begin{tabular}{|c|c|c|c|c|}
\hline \multirow[b]{2}{*}{ Variable } & \multicolumn{2}{|c|}{$\begin{array}{c}\text { Any Back Pain } \\
\text { Days }\end{array}$} & \multicolumn{2}{|c|}{ Pain Longer Than 14} \\
\hline & OR & $95 \% \mathrm{CI}$ & OR & $95 \%$ C.. \\
\hline Age $/ y r$ & 0.96 & {$[0.90-1.02]$} & 0.97 & {$[0.88-1.07]$} \\
\hline Weight $/ \mathrm{kg}$ & 1.02 & {$[0.99-1.05]$} & 1.01 & {$[0.98-1.06]$} \\
\hline Second Stage $/ \mathrm{hr}$ & 1.06 & {$[0.83-1.35]$} & 1.20 & {$[0.80-1.70]$} \\
\hline Nulliparity & 0.72 & {$[0.37-1.41]$} & $0.20^{*}$ & {$[0.06-0.69]$} \\
\hline
\end{tabular}

* $95 \% \mathrm{CI}$ excludes null value

ed there were 18 of $241(7.5 \%)(4.2-10.8 \%)$ who reported pain lasting for longer than 14 days.

Tables IV and V, contain the results of the stepwise multiple logistic regression procedure for the entire cohort (Table IV) and after excluding those women with a previous history of back pain (Table V). In the entire cohort a history of previous back pain was strongly associated with the presence of any back pain post-partum, odds ratio $43.85(9.97-1.92 .9)$. However, the association between a history of previous back pain and the occurrence of back pain lasting longer than 14 days was not significant (OR 2.16;0.7I -
6.58). Nulliparity was negatively associated with the occurrence of pain lasting for longer than 14 days for the entire cohort (OR $0.32 ; 0.11-0.94$ ) and when considering only those women with a negative previous history of back pain (OR $0.20 ; 0.06-0.69$ ). The other factors included in the model, age, weight and duration of the second stage of labour were not associated with the occurrence of any back pain or pain lasting for longer than 14 days. Other variables that were included in the stepwise logistic regression procedure but were not associated with any back pain or pain for longer than 14 days were, use of forceps, number of attempts at epidural placement, paraesthesias, patient assessment of painful insertion or the patients assessment of whether the epidural worked.

\section{Discussion}

The results of this study show that back pain is common after epidural anaesthesia but that, for most women, the symptoms do not last long. Many of the respondents reported a dull ache in the area of the insertion site which lasted a few days. This was not considered clinically important and, thus, the analysis of pain lasting for longer than 14 days was performed to eliminate this problem. The proportion of women who suffered with back pain for more than two weeks was much less. This is at odds with the study by Russell et al. ${ }^{6}$ who found that in the UK $34.5 \%$ of women who had epidural anaesthesia reported long term back pain when surveyed at three months postpartum. It is important to note that the frequency of back pain reported by women in this study, who did not have an epidural, was very similar (30.5\%) to the group that had had an epidural. When they compared the responses of the women at three months with self reported back pain at the time of delivery, these authors found that the majority of these women had reported back pain at the time of delivery. The true incidence of new long term back pain in women who delivered with an epidural was $7.5 \%$. The incidence of new long term back pain in women who delivered without an epidural was $6.9 \%$. Nevertheless, the current study found a much lower rate of long term back pain (defined as pain lasting for more than 14 days) in a population of patients who delivered with epidural anaesthesia. The differences in the timing of the surveys, four to six weeks $v$ s three months, seems unlikely to produce such a dramatic difference in the reported incidence of long term back pain.

Breen $e t a l .^{3}$ studied women in the Boston area and obtained follow-up at four to eight weeks post-partum and found that, when asked to report the presence of any back pain, $44 \%$ responded positively. Of that group, only $6.5 \%$ of the women rated their pain as severe. 
Unfortunately, it was not reported what proportion of the women reporting back pain had persistent symptoms. There was no association between the occurrence of back pain and the use of epidural anaesthesia in that study. The finding of a high rate of any reported back pain but a much lower rate of severe back pain is in keeping with this study's findings.

Macarthur et al. ${ }^{4}$ studied women in Montréal and found that post-partum back pain varied with time. It was most common immediately after delivery (48\%) declining to $22 \%$ at seven days and to $11 \%$ by six weeks. The authors did find an association between epidural anaesthesia and back pain on day one but not at day seven or six weeks. In a follow-up of that cohort at one year, Macarthur et $a l^{5}$ found an incidence of reported back pain of $12 \%$. There was no association between back pain and epidural anaesthesia.

Our results are more in keeping with Breen, ${ }^{3}$ and Macarthur ${ }^{4,5}$ than with the Russell ${ }^{6}$ study from the UK. There seems to be a difference in the reported incidence of long term back pain after labour and delivery between the UK and North America. Pain is a subjective experience and whether the difference reflects a difference in the cultural experience of pain, a difference in the reporting of pain or a true difference in the incidence of back pain is unclear.

It is somewhat surprising that, although a history of previous back pain was strongly predictive of the occurrence of any back pain, it was not predictive of pain lasting for longer than two weeks. The odds ratio for a previous history of back pain in the group with pain lasting for longer than two weeks was 2.16. It may be that the study did not have sufficient power to detect a difference, however the odds ratio in this group is much less than the $\mathbf{4 3 . 8 5}$ found for the "any back pain" group. This may reflect the possibility that pain that lasts more than two weeks after delivery is different in origin from that experienced previously by these women. A previous history of back pain was found to be a risk factor for the development of postpartum back pain by Russell. ${ }^{6}$

Nulliparity was found to be associated with a lower risk of post-partum back pain, although the odds ratio was < 1 for both 'any pain' and 'pain lasting more than two weeks' it was only statistically significant for the pain lasting more than two weeks. This is opposite to what was found by MacArthur. ${ }^{1}$ More recently, the prospective study of Russell ${ }^{6}$ found no association between back pain and parity. Maternal age, weight and the duration of the second stage of labour were not found to be predictive of post-partum back pain. The duration of the second stage of labour has been postulated as the important factor in the development of post-partum back pain, in that it reflects the time that a woman may have ligaments in her lower back excessively stretched during lithotomy positioning. This was not born out in this data.

It is important to stress that this study did not examine the association of post-partum back pain and epidural anaesthesia and, therefore, no comment about causation can be made. After some early retrospective reports suggested an association between long term back pain and epidural anaesthesia, ${ }^{1,2}$ more recent prospective studies have failed to show any association. ${ }^{3-6}$

In conclusion, back pain following epidural anaesthesia is common but only a small fraction of those people experience pain for more than two weeks. An increased risk of back pain following epidural anaesthesia was seen with a previous history of back pain, and nulliparity was associated with a decreased risk of experiencing back pain for more than two weeks.

\section{References}

1 MacArthur C, Lewis M, Knox FG, Crawford JS. Epidural anaesthesia and long term backache after childbirth. BMJ 1990; 301: 9-12.

2 Russell R, Groves P, Taub N, O'Dowd J, Reynolds $F$. Assessing long term backache after childbirth. BMJ 1993; 306: 1299-303.

3 Breen TW, Ransil BJ, Groves PA, Oriol NE. Factors associated with back pain after childbirth. Anesthesiology 1994; 81: 29-34.

4 Macarthur A, Macarthur C, Weeks S. Epidural anaesthesia and low back pain after delivery: a prospective cohort study. BMJ 1995; 311: 1336-9.

5 Macarthur AJ, Macarthur C, Weeks SK. Is epidural anaesthesia in labour associated with chronic low back pain? A prospective cohort study. Anesth Analg 1997; 85: 1066-70.

6 Russell $R$, Dundas $R$, Reynolds $F$. Long term backache after childbirth: prospective search for causative factors. BMJ 1996; 312: 1384-8.

7 Hosmer DW Jr, Lemeshow S. Applied Logistic Regression. New York: John Wiley \& Sons, 1989. 